Laura Bazzicalupo. Catedrática de Filosofía Política por el Dipartamento di Scienze politiche, sociali e della comunicazione de la Università degli Studi di Salerno. Coordina el Comité Científico del Doctorado en Filosofía, Historia y Teoría de las Instituciones jurídicas y políticas; también coordina a nivel nacional el proyecto Prin, titulado "Gubernamentalidad biopolítica". Es presidenta del currículum de la licenciatura de Ciencias Políticas y de las Relaciones Internacionales, Università degli Studi di Salerno. Sus intereses científicos son las problemáticas de las tecnologías gubernamentales, los procesos de subjetivación, los dispositivos del poder bioeconómicos y biopolíticos.

Contacto: 1.bazzicalupo@unisa.it 


\section{HISTORICIZACIÓN RADICAL, GENEALOGÍA DE LA GUBERNA- MENTALIDAD Y SUBJECTIVACIÓN POLÍTICA}

Laura Bazzicalupo

Università degi Studi di Salerno

\section{HIRADICAL HISTORICIZATION, GENEAOLOGY OF GOVERNMENTALITY AND POLITICAL SUBJECTIVATION}

Fecha de recepción 4 de marzo 2015; fecha de aceptación 9 de abril 2015. Este artículo se ha publicado en el ámbito del proyecto PRIN "Gubernamentalidad Biopolítica" promovido por el Dipartimento di Scienze Politiche, Sociali e della Comunicazione de la Università degli Studi di Salerno.

\section{Resumen}

El presente ensayo analiza el estancamiento que amenaza la forma de genealogía sociológica de la gubernamentalidad, hoy día muy difundida. Subrayando la natura- 
leza relacional del poder y la necesaria implicación de las resistencias en el poder que constrastan, ella no es capaz de llevar adelante una iniciativa. La recuperación, dentro del pensamiento foucaultiano, de la radical empiria e historicidad de los discursos 'partesanos' del historiador renunciando a un horizonte hermenéutico totalizante tal como puede ser la gubernamentalidad misma, se demuestra en la parresía política en la que 'el hecho' de la verdad singular y testimonial triunfa 'contra' aquella epistémica dominante.

\section{Palabras clave}

Foucault, gubernamentalidad, wirkliche Historie, politicidad.

\section{Abstract}

This essay focuses on the impasse threatening the sociological form of genealogy of governmentality, that is today widespread. Stressing the relational nature of power and therefore the necessary implication of the resistances in the power that contrast, it is incapable of a political antagonism. The recovery, in Foucault's thought, of the radical empiricism and historicity of the 'partisans' discourses of historian and denial of a hermeneutic totalizing horizon which may be even the governmentality, is confirmed by the political parresia where 'the fact' of the singular and testimonial truth states 'against' the dominant epistemic truth.

\section{Keywords}

Foucault, governmentality, wirkliche Historie, politicity.

\section{Politicidad del pensamiento y racionalización}

A veces, investigar el último Foucault es inquietante. De hecho, si por una parte no siempre se reconocen los caracteres del mensaje foucaultiano al cual estábamos acostumbrados, por otra parte perfeccionamos el análisis de estas últimas obras porque buscamos en ellas una clave para salir de una situación de estancamiento, de una claustrofóbica remisión a la gubernamentalidad neoliberal que se ha convertido —a pesar de Foucault - en una especie de escolástica, con efectos paralizantes desde un punto 
de vista político, a pesar de ser la categoría en la cual la genial analítica foucaultiana ha mostrado la máxima fecundidad con respecto a nuestro presente; incluso, esta capacidad heurística ha sido adoptada por estudios neoliberales, postcoloniales, neodeleuzianos y hasta por ampulosos estudios de derecho administrativo update. Y esta adopción implica el riesgo de un saber codificado, de una verdad epistémica y objetivante.

El círculo gubernamental subjetivación-sujeción puede convertirse en una trampa de la cual es imposible salir, una trampa que no está confirmada por la dificultad de una diferente subjetivación política, tanto más urgente cuanto más ardua.

$\mathrm{Y}$ este riesgo no puede sino trastornar a quien le reconozca a Foucault su elección de grabar directamente el pensamiento en la escena política rechazando todo tipo de pasaje a través de la filosofía política y el logos. A pesar de ser un pensamiento exento de consideraciones académicas, que anda por la vida y que ya es una costumbre, ha estado dispuesto a desmovilizar la codificación de su propio método, estimulado por la contingencia política.

Y eso que es evidente —y más veces se ha notado— la ambivalencia de los governmentality studies, desarrollados en el seno del pensamiento foucaultiano que empujan la categoría de la gubernamentalidad hacia una forma de racionalización. ${ }^{1}$ Trátese o no de racionalización, igual es una cuestión de fundamental importancia que nos induce a enfocar precisamente el nivel epistemológico del pensamiento foucaultiano, para preservar lo que es un gran proyecto de historicización y de incidencia política sobre ella. Hay que evitar que el importante tema de la transformación del poder en sentido gubernamental se neutralice en una dimensión epocal, que se convierta en una etapa de una historia de las ideas y que pierda la dimensión de la actual y contingente temporalidad, entendida como campo de fuerzas activas.

De ahí que mi intención sea reactivar la tensión epistemológica y práctica de la genealogía: dejar emerger el movimiento dinámico que tanto el discurso parresiástico, como el discurso del historiador y, de alguna manera, el mismo discurso del mercado, con su 'colocación' inmanente a la escena política y social, transmiten a la categoría de la gubernamentalidad.

Por lo contrario, la huella epistémica que Foucault nos ha dejado hoy día está bastante desatendida: una senda interrumpida, tal vez porque haya emergido, en la reflexión

\footnotetext{
1. Cfr., A. Barry, T. Osborne, N. Rose (eds.), Foucault and Political Reason: Liberalism, Neo-Liberalism and Rationalities of Government, UCL Press, London, 1996; P. Miller, N. Rose “Governing economic life”, en Economy and Society, 19, 1990; el reciente B. Golder (ed.), Re-reading Foucault: on Law, Power, and Rights, Routledge, London 2013; como crítica T. Lemke "Neoliberalismus, Staat und Selbsttechnologien: Ein kritischer Überblick über die governmentality studies", en Politische Vierteljahresschrift, 4,1, 2000.
} 
postfoucaultiana, el largo camino del naturalismo, que la transcribe en términos afirmativos, ontológicos. En este caso, Foucault se convierte en un pasaje, porque el objetivo es que se manifieste una autorregulación inmanente del devenir. A esta altura Foucault se vuelve residual, porque él no se interesa por la naturaleza, ni quiere hacerlo: su análisis atañe al fundamento y a su ausencia abgrund/grund, pero no se acerca al abismo de la vida como potencia autorregulativa. Para Foucault, el acceso a la 'naturaleza' —acuérdese la discusión con Chomski- o más aún a la vida, siempre han sido el fundamento de los dispositivos de control del viviente. ${ }^{2}$ Pararse antes, antes del fundamento, antes del origen: limitarse a la apariencia de lo que se ve y que se ha dicho realmente. Conocemos la mofa de Foucault hacia las investigaciones histórico-filosóficas que aspiran al secreto, a lo omitido, al murmullo del cual brotará la verdad y el sentido global.

El tema se explica con la muy apremiante fidelidad de Foucault a lo empírico y a la 'positividad', al nominalismo y al conductismo. Lo empírico no es sino una combinación de conexiones, accesibles solo a nivel de su inmanencia, que no solo no autoriza sino también contrasta de manera programática con cada acceso a la originariedad del fenómeno que, para Foucault, desarrolla una función de ocultación.

La perspectiva metodológica foucaultiana — de la que se habló mucho en los años de la Arqueología del saber y de Las palabras y las cosas y cuando se pasó a la genealogía-, perspectiva siempre relacionada coherentemente con esta absoluta 'fidelidad', que Deleuze define dermatológica, a lo visible y a lo dicho, hoy está descuidada tanto respecto de una gubernamentalidad como racionalización como respecto de un acceso al umbral naturalista, y eso ocurre justo hoy, cuando lo actual de la analítica del poder gubernamental y los estudios sobre la parresía ofrecen un cruce que podría cobrar una importancia fundamental para el pensamiento de la política.

Foucault esboza un complejo y multiforme proyecto de interpretación de la historicidad y de la ontología del presente como campo de fuerzas activas, irreducible a un solo plano-secuencia, tanto como poder gubernamental omnidifusivo, como biopotencia. Radicalizando el itinerario Hegel-Nietzsche, construye desde el principio el saber histórico como análisis genealógico del acontecimiento, de su diferencialidad e irreducibilidad a lo universal del significado. Con la evenementalisation de la historia se esquivan las estructuras necesarias y se dejan emerger prácticas, programas y dispositivos con efectos discriminantes. ${ }^{3}$ De ahí que el dispositivo gubernamental no tuviera que corresponder a

2. N. Chomsky, M. Foucault, The Chomsky Foucault Debate: on Human Nature, Norton \& Company, New York, 2006. 3. M. Foucault, L'Ordre du discours, Gallimard, Paris, 1971, pp 59-60; cfr., también el concepto de événementialisation, en “Qu'est-ce que la critique?", en Bullettin de la Societé française de philosophie, VXXXIV, 1990, pp. 42-45, p. 48. 
un conjunto compacto sino a una agrupación de positividades dispersas, causadas por los efectos de prácticas anónimas. Racionalidad múltiple y estrategias locales en lugar de un único proceso de racionalización. Para Foucault, la racionalización es algo provocador, tal como el riesgo claramente relacionado con su mismo trabajo:

Par gouvernamentalité jentends l’ensemble costitué par les istitution, les procedures, analyses et reflections, les calculs et les tactiques... par guvernamentalité j'entendes la tendance, la ligne de force qui, dans tout l'Occident, ni a pas cessé de conduire..., vers la preminence de ce type de pouvoir... Enfin pour guvernamentalité je crois qu'il faut entendre le processus... par le quel l’etat...s'est trouvé petit à petit gouvernamentalisé. ${ }^{4}$

Este pasaje muy citado varía entre correspondencia con la perdida concreción de los poderes que halla una agregación nominalista en el término (j'entends l'ensemble), entre totalización epocal (tout l'Occident ni a pas cessé de conduir vers la preminence de ce type de pouvoir) y teleología tendencial (la ligne de force... le processus), corriendo el riesgo de autorrepresentarse en el círculo de la racionalización histórica. Y si hay racionalización no hay sino dos posibilidades: la tecnocracia que nos somete a la racionalidad "triunfante" o la valorización simbólica de las nociones, con tal de que las veridiciones sean reaccionarias o progresistas. ${ }^{5} \mathrm{Y}$ se pierde la politicidad de hacer la historia típica de Foucault: su genealogía de la manera como la verdad se establece coincide con una política de la verdad, de las condiciones de acceso a lo real.

La actuación política coincide con la colocación a nivel de las fuerzas activas y conflictuales. Y la genealogía es aquel punto de vista que 've' el conflicto, el residuo diferencial que, cada vez, emerge en las relaciones gubernamentales si se analizan bajo la óptica genealógica. ${ }^{6}$ Además, el problema no atañe solo al tema de la gubernamentalidad. También los ensayos sobre la epimeleia seauton y, a veces, también aquellos sobre la parresía parecen revelar — con su doble interés hacia la historia de las ideas y el evento de la subjetividad heroica — la evenemencialización: se examinan — tal como en Nacimiento de la biopolítica - teorías, doctrinas, obras literarias y filosóficas predominantes

4. M. Foucault, Sécurité, territoire, population. Course au Collége de France (1977-1978), Seuil, Paris, 2004, pp. 111-112. 5. M. Foucault, "Sur l'archéologie des sciences. Réponse au Cercle d'épistémologie”, en Id., Dits et écrits, Gallimard, Paris, 1994, I, 59, pp. 656-730, p. 727,

6. H.L. Dreyfus, P. Rabinow, Michel Foucault, Beyond Structuralism and Hermeneutics, The University of Chicago Press, Chicago, 1982; cfr., en ibidem M. Foucault, The Subject and Power, pp. 208-226; Id., "Réponse à une question”, en Esprit, 371, mai 1968, pp. 850-874, publicado en Dits et écrits, I, 58. 
respecto de acontecimientos o estructuras materiales que posibilitan aquellas obras y su eficacia. Por lo tanto, de aquellas teorías u obras literarias y no de estas condiciones de posibilidad material y concreta emerge un sujeto ético-libre que está caracterizado, de manera problemática, por el cuidado de sí mismo y por la distancia con respecto a su propia subjetivación epistémica. La misma hipótesis de una parresía transhistórica y cripto-ideal-típica parece 'fundada' y puede desconcertar en un autor que afirma que no existen constantes en la historia. ${ }^{7}$ Para Foucault, la relación entre política e historia es algo diferente de los idealtipos: incluso malgré lui, es más fiel a la inmanencia del agente al campo de acción. Aquella inmanencia ciega que había hechizado a Foucault en la antigubernamentalidad liberal de manera considerable: la opacidad de la totalidad del mercado como condición de la elección del libre agente económico, cuyo campo de acción es un cruce de contingencias y necesidades precarias.

\section{Historicización radical: niveles que se cruzan}

Intentemos reconstruir el juego de niveles en el proyecto foucaultiano de historicización: condenado por ser abstrayente/mistificador, al nivel de la filosofía de la historia y de la racionalidad jurídica y filosófica (que conoce el sentido del devenir y polariza la dicotomía poder y libertad) responde polémicamente el programa escogido en la genealogía, que analiza las prácticas desde el punto de vista de su disgregación y enfoca en ellas las relaciones gubernamentales y la interdependencia de los supuestos polos opositivos, deconstruyendo el momento metafísico de la contradicción.

Sin embargo, solo un ulterior nivel de orientación, totalmente disuelto en la inmanencia de cada polo de aquellas relaciones, que se mueva en un entorno opaco, en el cual el sentido o la valorización de cada vector no es predecible ni controlable y cobra sentido solo ex post, pues solo cuando el vector renuncia a la visión de todo el campo de combate gubernamental y adquiere las veridiciones partisanas de afrontamiento encareciendo su inquieta contraposición (aunque — claro está — sea desconstruible en la interdependencia del gobierno), solo a este nivel de orientación, arriesgado y conjetural, 'actúa' y encuentra la fuerza y el valor de hacerlo. Y actúa (posible aunque no necesariamente) con la conciencia genealógica de la politicidad de las verdades contra las cuales y con las cuales combate.

7. Cfr., S. Chignola, "Phantasiebildern/histoire fiction Weber e Foucault", en P. Cesaroni, S. Chignola (eds.), La forza del vero. Un seminario sui Corsi di Michel Foucault al Collège de France (19781-1984), Ombre corte, Verona, 2013 pp. 30-70 en ibidem J. Revel, Passeggiate, piccoli excursus e regimi di storicità, pp. 161-179. 
Tal vez esta dinámica de niveles remitiera a una descomposición del proceso de subjetivación y es probable que de esta exigencia nazca la contaminación lacaniana de mucha filosofía postfoucaultiana. Sin embargo, este no es un problema que le interese a Foucault, quien no se interesa de la situación —al mismo tiempo conflictual y gubernamental - que se realiza "dentro" del proceso de subjetivación. Foucault le teme a la interiorización y a la originariedad trascendental que el sujeto adquiriría y considera un eje fundamental de su método la analítica de lo visible y de las prácticas. Se queda en la superficie dermatológica: y esta presenta una serie de niveles de discurso así como de análisis, niveles de elección que dividen el suceso en varios grupos: y sobre ellos tenemos que reflexionar. ¿Y entonces? Hecha excepción de toda descomposición ontológica de la psique, entonces la actuación política solo es posible si las relaciones gubernamentales se consideran de manera realmente genealógica y no sistémica.

La crítica ilustrada nos ofrece un ejemplo del cruce de los niveles de perspectiva, en la parcial superposición del nivel jurídico-institucional y metafísico de las verdades expuestas (insertadas en una construcción de filosofía de la historia) respecto del nivel de veridición de parte y parresiástica que contrapone concretamente un poder/verdad a otro poder/verdad, el del estado absoluto, a su vez concreto y activo. ${ }^{8}$ Los niveles se cruzan: la filosofía de la historia considerada junto con sus verdades jurídicas genera una práctica jurisdiccional agonística contextualizada como la universal visión jurídico-institucional moderna. De manera paradójica, esta última trascendencia es precisamente el nivel que la veridición crítica escoge para ganar su batalla; no dentro, no demasiado sumidos en la inmanencia de una veridición reactiva que oscurecería su identificabilidad política. Deberíamos preguntarnos si, antes que una contraposición algo simplista entre verdades epistémicas objetivantes y verdades aletúrgicas testimoniales, nos encontramos ante un cambio de perspectiva y de enfoque. En mi opinión, se trata del imperativo epistémico de meterse en el fenómeno, de someterse a este, con tal de obedecer a las veridiciones que construyen las subjetivaciones sometiéndolas, y de liberar la dimensión aletúrgica, no objetivante y no epistémica de aquellas mismas subjetivaciones. El focus se desplaza de los contenidos universalizantes a su capacidad de construir subjetividades autogobernadas, estilos de vida y de contraconducta.

Sin embargo, este cambio no solo conlleva una opacidad con respecto al 'sentido' global (del cual es realmente difícil afirmar si es una tendencia epocal, una línea de fuerza o un proceso dominante en Occidente), sino también una opacidad respecto de la dependencia del agente de la verdad institucionalizada.

8. M. Foucault, “Qu'est-ce que la critique ?”, pp. 35-63; Id., “Qu'est-ce que les Lumières?”, en Dits et écrits, IV, Gallimard, Paris, 1994, pp. 562-578. 
A esta altura es difícil decir si es indispensable la askesis que permite guardar las distancias y la deprise que rompe la inmanencia histórica: procesos ético/filosóficos improbables en las numerosas actuaciones colectivas. O bien si es suficiente la forma o el cariz ético que podemos considerar como repetición diferente: variación sin oposición, que más fácilmente se imagina en la subjetivación gubernamental no interdictiva del neoliberalismo. De todas formas, tenemos que partir de un suceso, de una contingencia que se realiza o no se realiza: una resistencia, un comportamiento de disenso, un viviente que afirma otra vida; un pensamiento "foco de experiencia", 9 que levanta la voz y que causa un revuelo: ¿de dónde levanta su voz?

\section{Gubernamentalidad entre genealogía y racionalización}

¿Y qué es la gubernamentalidad desde un punto de vista metódico? ¿De qué tipo de aproximación epistémica deriva? De la genealogía, claro está, y está relacionada con ella con una especial afinidad que aumenta los riesgos de una racionalización.

Si ya la arqueología se oponía a la filosofía de la historia, de la conciencia y del sujeto, la genealogía elige - de manera provocadora - una manera nietzscheana de enlazar historia y praxis, mejor dicho historia monumental y una actuación política que no sea humillada por la prevaricación teórica. ${ }^{10}$ Además, se juntan varios indicadores que son importantes para señalar una especial relación con el equilibrio gubernamental de los poderes.

Antes que todo, la inseparabilidad de los conocimientos de las prácticas de poder: lo cual significa que no se buscan las condiciones racionales que posibilitan el suceso sino las condiciones materiales, las que incluyen los elementos heterogéneos e inconexos que han favorecido el evento contingente ese y no otro. No hay Zeitgeist, no hay un estilo común, ni mucho menos una racionalidad que subyace a los sucesos: el objetivo es el suceso mismo, el residuo discontinuo y contingente que no puede ser reincorporado en condiciones racionales que lo causen. La genealogía quiere captar la especificidad de los sucesos, lejos de toda finalidad monótona: ${ }^{11}$ no hay esencias, leyes, finalidades metafísicas. Busca la discontinuidad. Rehuye de la profundidad: deja aparecer los sucesos

9. M. Foucault., Le gouvernement de soi et des autres. Cours au Collège de France (1982-1983), Gallimard-Seuil, Paris, 2008 p. 13. 10. F. Nietzsche, Unzeitgemässe Betrachtungen. Zweites Stück: Vom Nutzen und Nachtheil der Historie für das Leben, in Sämtliche Werke. Kritischen Gesamtausgabe, Band 1, W. de Gruyter, Berlin-New York, 1988.

11. Cfr., M. Foucault, "Nietzsche, la généalogie, l'histoire", en S. Bachelard et al. (eds.), Hommage à Jean Hyppolite, Puf, Paris, 1971, pp. 145-172. 
superficiales, los detalles, los cambios pequeños ${ }^{12}$. El genealogista escribe la historia real, la wirkliche Historie: no totaliza la historia, ni tampoco su desarrollo interior. ${ }^{13} \mathrm{Ve}$ todo lo que se mueve.

Bajo este punto de vista, más vale la experiencia que las generalizaciones teóricas, científicas o no, que de la experiencia sacan su eficacia, inteligibilidad y autoridad. Las prácticas son difusivas, diseminadas, complejas, pero también contingentes y estratificadas y cualquier tentativa de sintetizar lo que ocurre no puede ser sino una peligrosa distorsión. ¿Peligrosa? Si toda historiografía que tenga un sentido está caracterizada por un propósito pragmático no se escribe sino la historia del presente, historia para la política. El genealogista conoce "el secreto por el cual las cosas no tienen esencia o que su esencia ha sido construida pieza por pieza a partir de imágenes que se les presentan como ajenas", ${ }^{14}$ aunque al mismo tiempo: "nadie puede asumirse la responsabilidad de una excepción, nadie puede jactarse de ella; ella siempre se produce en un intersticio". ${ }^{15}$ Así que aparece el concepto de excepción, que juega un papel fundamental en el análisis foucaultiano de la gubernamentalidad, y también en aquel de la parresía. También es interesante la noción de intersticio. La relación de las fuerzas que actúan en una situación histórica cualquiera se puede dar gracias al espacio, el intersticio, que define a estas fuerzas. Este ámbito de inmanencia es fundamental para el genealogista: sus coordenadas derivan de las prácticas que se han estabilizado. Y en este aparecen maniobras sociales relevantes para los que están comprometidos, conflictos que definen este mismo espacio de inmanencia. Esto es el meollo: los sujetos no preexisten, aparecen en aquel campo de batalla sobre el cual desarrollan sus funciones. Según la opinión comportamentalista del genealogista, el mundo es lo que aparece. Y aparecen conflictos, relaciones de fuerza; el genealogista detecta su ritual con obligaciones y derechos que no dependen del sujeto sino lo hacen funcionar.

Añadamos algunas notas de Dreyfus-Rabinow: el "déchiffrement" de la genealogía es la constatación de que "las prácticas sociales se prestan a una inteligibilidad totalmente diferente de la poseída por los actores"; además — por lo que nos interesa— el genealogista observa las cosas desde lejos. ${ }^{16}$

\footnotetext{
12. La profundidad se devuelve como secreto absolutamente superficial, cfr., M. Foucault, Nietzsche, Minuit, Paris, 1967, pp. 186-187: similar es el concepto deleuziana de suceso de derivación nietzscheana: G. Deleuze, Nietzsche et la philosophie, Puf, Paris, 1962, p. 4.

13. En el hombre, nada es bastante estable —ni siquiera su cuerpo— para comprender los demás hombres y reconocerse en ellos. Cfr., M. Foucault, "Nietzsche, la généalogie, l'histoire”, p. 160.

14. Ibid., p. 148.

15. Ibid., p. 156.

16. H. Dreyfus P. Rabinow, Michel Foucault, Beyond Structuralism and Hermeneutics, p. 22.
} 
Ahora bien, ¿por qué he mencionado, aunque de manera sintética, estas muy conocidas características del método genealógico? Empirismo, positividad, materialidad, suceso, singularidad, excepción, discontinuidad, intersticios y ámbitos de fuerza, distancia entre los actores y el saber de los efectos, imprevisibilidad, historia visible, historia concreta, efectiva, historias plurales, pérdidas, no totalizables. El diagnóstico sobre el presente de Foucault — que hoy nos estimula más - enfoca los caracteres del poder neoliberal, su modus gubernamental, biopolítico en sentido amplio, con el cual se gobiernan las vidas. Como en toda genealogía, 'vemos' la gubernamentalidad a través de conflictos, los residuos, que esbozan su campo de inmanencia, es decir, a través de las resistencias de las vidas que no quieren hacerse gobernar tanto o de esta manera. Es la resistencia la que quiebra el continuum de una posible racionalización y deja emerger el gobierno de las vidas como una relación de poder, inestable y específica, diferente dependiendo de los lugares y de los tiempos.

Sin embargo, notamos que muchos de los caracteres de los que hemos hablado a lo largo del enfoque genealógico encuentran una correspondencia y resonancia en el escenario gubernamental. También en este caso la síntesis pierde su importancia: nadie la busca, y lo mismo le ocurre a la filosofía de la historia; aquí coexisten elementos heterogéneos en una inestable y no identitaria inclusividad y se evidencia sin disimulación la lógica estratégica de los saberes, sobre todo del saber económico que atraviesa y une los vectores perdidos del campo de fuerza, sin obligarlos en una síntesis de sentido: la lógica de la organización dirigida a la optimización a través de la competición es el medium que se difunde unificando el ámbito sin sintetizarlo; además, no se exige un saber totalizante acerca del sentido o de la orientación de las elecciones: es más, debido al modelo del mercado y de los estándares normativos ex post que sustituyen las leyes, los estatus, un saber global malinterpretaría el libre funcionamiento de los poderes sociales; además, cada uno no tiene una posición aislada y contrapuesta sino — a pesar del imaginario individualista — están caracterizados por una dependencia relativa de emplazamiento, puesta en evidencia por la evaluación competitiva cuya tarea es manejar la anarquía de los poderes. Esto significa que si el poder no debería aparecer sino en el conflicto/resistencia, más bien este se manifiesta en una jerarquización de las posiciones que dependen de los estándares comparativos que, a su vez, remiten a las libres elecciones de cada cual.

Esta implicación entre gubernamentalidad y punto de vista genealógico que la patentiza no solo muestra que la controversia antitrascendental que dio origen a la misma elección genealógica ya no tiene sentido, sino también que está cargada de efectos arriesgados. 
¿Qué significa ver genealógicamente (y valorizar desde un punto de vista gubernamental) la interdependencia de los polos de la relación de poder? Significa que, a pesar de que la genealogía nos empuje hacia un concepto de gubernamentalidad que obliga el continuum hacia el camino de la irreducible pluralidad de las situaciones y de los acontecimientos, no obstante estos acontecimientos patenticen la discontinuidad, el residuo, por mucho que el objetivo sea la emergencia del suceso resistencial, el mismo hecho de que el objeto de gobierno aparece caracterizado por la excepción que lo convierte en gobernable y por la reconducción de la resistencia a la dependencia recíproca se incorpora perfectamente en el proyecto gubernamental, lo repite, pues lo racionaliza. Se mantienen la diferencia y la conflictualidad y se encauzan a la comparación competitiva cuyos criterios emergen del ciego cruce de los comportamientos y de las elecciones: y todas las responsabilidades recaen sobre ellas. Pues claro, toda tecnología de gobierno implica una racionalidad política que, de alguna manera, es bifrontal: por una parte, el eje conceptual representa y racionaliza técnicas de ejercicio del poder, un campo discursivo que localiza objetos, límites, argumentaciones justificativas y legitimaciones, racionalidades normativas y reglas: pues un tema de saberes/verdades, alrededor del cual se estructura el poder; ${ }^{17}$ por otra parte, permite que surja o, mejor dicho, recibe la visibilidad de una específica y concreta forma de intervención del gobierno: los dos planos se condicionan recíprocamente en una constante transformación, según la premisa nietzscheana de la impureza constitutiva, de la inevitable contaminación de las ciencias y de los saberes relativos al objeto de gobierno. Si embargo, hay algo más que actúa en el cruce método-objeto, genealogía-gubernamentalidad: podemos decir que, bajo el término gubernamental, la genealogía ensambla un dispositivo que construye de manera procesal su propio objeto - individuos y población- (es decir, lo coloca en la dimensión de su gubernamentalidad), sometiéndose a su concreta pluralización y haciendo emerger los aspectos problemáticos (las eventuales faltas y desproporciones), para predisponer al mismo tiempo las estrategias necesarias para mejorarlo: problem solving. El objeto gubernamental que brota del análisis genealógico y que solo está orientado hacia las estrategias, a su vez es claramente estratégico y racionalizante: construye y define con la finalidad de controlar, tal como lo demuestra la lógica estructural pragmático-operacional de organización y dirección que lo caracteriza. La ontología sucumbe ante este tipo de enfoque ajustado a una realidad no definible a priori, conyuntural y de emergencia.

17. "Combination of certain techniques for analyzing concepts and of certain techniques for writing their history": A. I., Davidson, The Emergence of Sexuality: Historical Epistemology and the Formation of Concepts, Harvard University Press, Cambridge (Mass.), 2001, p. 179, cfr., también Id., “Régimes de pouvoir et régimes de vérité”, en M. Foucault, Philosophie. Anthologie, Gallimard, Paris, 2004, pp. 381-392. 


\section{Cambios de niveles: emergencias, adaptaciones y rupturas}

Damos por sentado que el objetivo foucaultiano era individuar — en aquellas viscosas máquinas de las relaciones de poder gubernamental - el momento de las luchas de resistencia y los vectores de contrapoder. Sin embargo, la actual y débil formación de sujetos políticos resistentes y antagonistas parece precisamente remitir a la capacidad de la gubernamentalidad neoliberal de metabolizar y dejar coexistir formas incoherentes en un conjunto sin unión; las excepciones no interrumpen, no protestan: se convierten en puntos fuertes del control y de la captura. De la misma manera, la excepción siempre es estimulada y valorizada. La gubernamentalidad se presenta como un dispositivo que produce excepciones que racionaliza y captura ininterrumpidamente: de ahí que coincide tanto con las prácticas de racionalización como con el nomen genealógico que debería evidenciarlas como resistencias. El mismo análisis foucaultiano fluctúa entre un neoliberalismo antigubernamental y una gubernamentalidad neoliberal que ejerce un control.

Por lo tanto, ¿debemos dejar correr la genealogía y, junto con ella, la política de la verdad, o bien el objetivo se logra con una rotación epistémica que, sin desatender el ámbito de la genealogía, dirige el interés del filósofo — tal como aquel del actor- dentro del campo de observación?

No se trata de una retractación metodológica. En efecto, precisamente el hecho de estar dentro del campo de observación ha caracterizado al concreto episteme foucaultiano. Desde siempre se ha tratado de un negativismo nominalista, que a universales como la locura, el crimen, la sexualidad (ahora la gubernamentalidad) sustituía el análisis de las experiencias históricas individuales. Más bien se trata de una recodificación del método que permita seguir con el tema de una historicización radical y por lo tanto política, radicalizando en sentido estricto la limitación, la contingencia y la pluralidad de las miradas subjetivas sumergidas en la totalidad de los acontecimientos. ${ }^{18}$ Solo el nivel de estas miradas genera la visibilidad de perspectiva de las resistencias sin englobarlas en la relación de poder a la cual pertenecen y que solo en la cual son reales.

Más allá de la patente referencia a Nietzsche, llamaría esta posición maquiavélica - hecha excepción del equívoco foucaultiano de Maquiavelo- que se debería destacar en el último Foucault. Si llevamos a cabo una historicización radical de la aplicación del análisis, los contra-comportamientos que convierten la gubernamentalidad en sentido antigubernamental adquieren un perfil más neto y visible en el marco

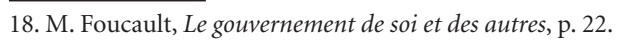


atonal de la relación gubernamental. Y las experiencias de cínica parresía —en sentido literal, encarnación, hacerse carne de una improbable libertad natural y de una verdad completa que se opone a las opiniones falsas e hipócritas del mundo- adquieren el carácter agonístico de ordálico desafío, que manifiesta la genuina e innegable politicidad del pensamiento.

Tal como ya hemos dicho, se trata de un problema de niveles antes que de cambio de perspectiva.

Nuestra pregunta es: ¿a qué nivel tenemos que cortar el suceso para que el dato de la crítica (como de la parresía, de la resistencia, de la verídica oposición a la verdad dominante) no quede neutralizado por aquel de la gubernamentalidad y del sistema de verdades que la respalda y que, muy probablemente, la estimuló? Para Foucault, la respuesta siempre es la misma: aquel que "restituye al discurso su carácter de suceso", ${ }^{19}$ de emergencia. Sin embargo, la emergencia 'evenemencial' se halla en la gubernamentalidad neoliberal heterogénea y antirrepresentativa, en una arriesgada sugestión que la contamina: opacidad, diferencialidad, desestructuración, dispersión de los poderes se convierten en racionalidad política que necesita ser estimulada y controlada.

Entonces llega a ser necesario profundizar el asunto, hundirse en la misma racionalidad de gobierno para hallarse en sus situaciones diferenciales, para abrazar aquel nivel dermatológico de las conflictualidades y de las resistencias: no ver o renegar las interdependencias.

De esa manera, el antiguo paradigma del poder batalla, aplicado a aquel del gobierno, lo vuelve a encender: si y solo si la mirada subjetiva de parte nota un vacío y una contradicción ahí donde no hay ni vacío ni contradicción. Solo si la discontinuidad resiste ante el continuum que las veridiciones gubernamentales construyen se manifiesta el punto de vista de quien toma posición, estructurando 'libremente' el campo de acción. La coyuntura regresa a lo suyo; adquiere el semblante — que nosotros los espectadores percibimos - de una fractura que parte el tiempo en miles de posibles puntos. Tal como en el discurso del historiador quien nos comunica la conflictualidad, el antagonismo entre grupos, entre razas: poder/batalla. ${ }^{20}$ En Hay que defender la sociedad, Foucault contrapone el modelo bélico y las teorías contractualistas con la finalidad de vislumbrar, en el secreto resentimiento de los vencidos y en su contrahistoria, la persistencia de

19. M. Foucault, L'Ordre du discours, p. 40.

20. El estudio de la microfísica del poder como modelo se le confiere la batalla perpetua antes que el contrato que establece una cesión, o la conquista que se apodera de un dominio. Cfr., M. Foucault, Surveiller et punir. Naissance de la prison, Gallimard, Paris, 1975, p. 31. Cfr., M. Senellart, “Michel Foucault: Gouvernementalité et raison d’État, en M. Gauchet, P. Manet, P. Rosanvallon (eds.), Situations de la démocratie. Démocratie: l'ancien et le neuf. L’historicisme et ses ennemis. Passé présent, Pensée Politique, Gallimard-Seuil, Paris, 1993, pp. 276-303. 
una irreducible conflictualidad ${ }^{21}$. El razonamiento histórico (histórico-partesano, histórico-político y, claro está, no aquel filosófico-histórico), aquel de estilo tucidídeo, se aparta de toda universalidad; detectando las posiciones antagonistas, opera, realiza (no podemos sino pensar en la verdad efectual de Maquiavelo) la disposición de las partes, la verdad como victoria de parte (la wirkliche Historie de Nietzsche $)^{22}$.

Es superfluo recordar que, con el pasaje del poder/batalla al poder/gobierno, la relación de poder llega a ser más compleja: entran en juego los factores oblativos, las modalidades de la cura, las finalidades protectivas-incrementativas de la vida biopolíticas en sentido amplio y se pone en juego la función productora de subjetivación del poder gubernamental, no claramente contrapuesto al poder del gobernado...: ¿y la lucha? Siendo el gobierno acción respecto de las acciones de los demás, se valoriza una forma de libertad dependiente y por consiguiente, no hay ninguna discusión cara a cara de poder $y$ de libertad que sea recíprocamente exclusiva. ${ }^{23}$ Entonces, ya hemos dicho que la genealogía se encuentra frente e frente con los dispositivos gubernamentales que incluyen, de manera relacional y con una dependencia recíproca, a los polos del conflicto. Aun queriendo radicalizar el punto de vista genealógico, pensado en la óptica de la discontinuidad — atestiguando el fracaso estructural de la sujeción—, esta queda incluida en el dispositivo y no logra emerger en la forma del afrontamiento. No podremos ver el residuo con respecto a la sujeción, lo discontinuo de la resistencia sino como infinito aplazamiento de sujeción y subjetivación.

Libertad pero sin afrontamiento: pues, adaptación. ¿Por ese motivo acaba la lucha de las verdades que caracterizaba al discurso del histórico? En el mismo ensayo, reivindicando el fuerte enlace del análisis empírico con las relaciones de poder vinculadas con el presente, Foucault insiste en considerar como punto de partida las formas de resistencia opuestas a las varias formas de poder. Con otra metáfora, este (método) consiste en utilizar estas resistencias como un catalizador químico que permita poner en evidencia las relaciones de poder, localizar su posición, detectar sus puntos de aplicación y los métodos empleados. Antes que analizar el poder desde el punto de vista de su racionalidad interna, es menester analizar las relaciones de poder por medio del antagonismo de las estrategias. ${ }^{24} \mathrm{El}$ antagonismo de las estrategias da a conocer la disposición de las partes antagónicas, las 'localiza', descubre sus puntos de fuerza y de debilidad, lo que separa una fuerza de la otra, no lo que las une: estrategias de lucha en las que las dos fuerzas

21. M. Foucault, Il faut défendre la société. Cours au Collège de France (1975-1976), Gallimard-Seuil, Paris, 1997, pp. 48-53. 22. M. Foucault, Nietzsche, la généalogie, l’histoire, p. 159.

23. Cfr., M. Foucault, The Subject and Power, p. 221.

24. Cfr., ibid., p. 211. 
(que Senellart considera ser justamente numerosas) ${ }^{25}$ no se sobreponen, no pierden su específica naturaleza, en fin, no se confunden. Cada cual es para la otra una especie de límite permanente, un punto de posible cambio total. ${ }^{26}$

Este es el programa del antagonismo político, del choque frontal de las veridiciones (tal como en el caso de la crítica y de la parresía), que marcan fronteras determinadas porque están relacionadas con la diferenciación entre verdadero y falso y si, por una parte, apoyan las estrategias, por otra parte, lo hacen a través del énfasis de la contraposición. Este énfasis no es nada secundario porque precisamente en la divulgación y perentoriedad del gesto opositivo se asienta el efecto político y la capacidad de servir como ejemplo. Pues claro, la situación es mucho más compleja que la de una sencilla hipótesis del poder/batalla: antes que de un esencial antagonismo sería mejor hablar de un agonismo, de una relación que, al mismo tiempo, es exhortación y lucha. ${ }^{27}$

Sin embargo, en la parresía, el antagonismo existe y emerge de manera decidida, y está relacionado con aquella virtud del valor y con aquel desafío provocatorio llamado a garantizar el mayor valor, la diferencialidad ética de la verdad atestiguada con respecto a aquella dominante. La relación de poder es un desafío entre dos adversarios.

Para Foucault es fundamental la posibilidad de decodificar estos mismos sucesos desde el interior de una historia de las luchas o bien desde el punto de vista de las relaciones de $\operatorname{poder}^{28}$. El eje de esta preciosa sugerencia es el 'desde el interior', que origina las luchas.

Dependiendo de la dirección de la mirada y de su inmanencia respecto del campo de observación, se nos darán significados, encadenamientos, intelegibilidades diferentes que se refieren a la misma realidad histórica, dejando por sentado que el análisis que evidencia las luchas no puede sino remitir a aquel que enfoca la adaptación gubernamental: se combinan y remiten el uno al otro. En los dos casos, se trata de formas de historicización radical que, reconociendo su propia copertenencia al nivel de inmanencia descrito, definen el decir-la-verdad en toda su contingencia, aunque solo una nos proporcione la perspectividad subjetiva del conflicto.

Si ante la mirada que se mantiene coherente con la inmanencia histórica sin excederse de ella no sobresaldrá la perspectiva revolucionaria global ni la guerra dicotómica y frontal, sino muchas prácticas individuales de transgresión y contraposición, de

25. M. Senellart, en "Michel Foucault: Gouvernementalité et raison d’État, subraya el regreso a la multiplicidad de la batalla más allá de toda teleología revolucionaria y de cualquier estructura binaria de contraposición; Foucault nos dice que toda estrategia de afrontamiento aspira a convertirse en una relación estable de gobierno y a 'vencer' la resistencia. Pero esto ocurrirá solo de forma provisional, porque la relación de gobierno levantará otra resistencia.

26. Cfr., M. Foucault, The Subject and Power, p. 225.

27. Cfr., ibid., p. 222.

28. Cfr., ibid., p. 226. 
contradicción pues, también a su eficacia social, cultural y política no se le debe quitar importancia, porque manifiesta un nivel del discurso en el cual justamente el antagonismo y el choque son fundamentales. Se tratará de luchas transversales, siempre infra-gubernamentales, contra el 'enemigo inmediato' antes que contra el 'enemigo principal'; se tratará de luchas anárquicas que aspiran a la 'diferencia' tal como aquellas del ‘ 68 , y siempre tienen que ver con la pregunta ‘quiénes somos'? y con el rechazo radical de las objetivaciones verídicas gubernamentales tanto científicas como administrativas, y con las formas de sujeción de la subjetividad. ${ }^{29}$ Contraponerse al sello que nos convierte en sujetos sujetados conlleva algo más que una adaptación: una contraposición que, a pesar de reducirse en la práctica de resistencia, se basa en otra veridición, contrapuesta y dicotómica, o bien tan fuertemente fiel a la verdad dominante como para darle un vuelco justo cuando estaba tomándola al pie de la letra.

Las prácticas parresiásticas transmiten a las veridiciones dominantes repeticiones-variaciones que - lo notamos muy bien en la parresía cínica respecto del grupo de aquella socrática - las doblegan, las llevan al extremo. Sin embargo, se trata de adecuaciones que se viven y se consideran como un desgarramiento, un desplazamiento frontal y de la misma manera son percibidas también por quien asiste a la situación.

Más que una verdad aletúrgica contra aquella epistémica, nos encontramos con una radicalización y una repetición que implica una diferencia: la verdad dominante se repite, se demuda con una mueca, Butler diría: una parodia. Este es el “juego de los espejos” de la parresía; la parresía cínica es el espejo roto de la filosofía dominante y, pues, de una forma de gubernamentalidad. Una repetición que no solo no excluye la diferenciación ética, sino que llega a romper el espejo en el que se refleja. Sin embargo, la radicalización es tan violenta como para cortar el hilo, la trama, el tejido mismo de la adaptación: cuando alguien se expone a la muerte por la verdad, erradica cualquier consenso biopolítico gubernamental, a partir de aquel hobbesiano. Es el proyecto conyuntural de la relación consigo mismo, el plan de la ontología histórica del sí, es decir, el plan de la ética como política ${ }^{30}$. Este plan depende de la gubernamentalidad aunque la niegue: es parcial y discontinuo respecto de esta.

Traducción del italiano de M. Colucciello

\footnotetext{
29. Tal vez hoy día el objetivo principal no sea descubrir qué somos, sino más bien rechazar lo qué somos. Cfr., ibid., p. 224. 30. "[...] I would more or less agree with the idea that in fact what interests me is much more morals than politics or, in any case, politics as an ethics", M. Foucault "Politics and Ethics. An Interview”, in P. Rabinow (ed.), The Foucault Reader, Pantheon Books, New York, 1984, p. 375.
} 